\title{
Procesos que Protegen el Patrimonio de los Menores
}

LILIANA FERNANDA MORENO RIVEROS

\begin{abstract}
Abogada de la Universidad Libre. Especialista en Derecho de Familia de la Universidad Externado de Colombia y Especialista en Instituciones Jurídico Procesales de la Universidad Nacional de Colombia. Docente de la Corporación Universitaria del Meta.
\end{abstract}

Dentro de los muchos tratados internacionales que ha firmado y ratificado Colombia encontramos la Convención sobre los Derechos del Niño del 20 de noviembre de $1989^{1}$, primer instrumento internacional jurídicamente vinculante para Colombia.

LoscuatroprincipiosfundamentalesdelaConvenciónson:

I. La no discriminación.

II. La dedicación al interés superior del niño.

III. El derecho a la vida, la supervivencia y desarrollo.

IV. Respeto por los puntos de vista del niño.

Todos los derechos que se definen en la Convención son inherentes a la dignidad humana y el desarrollo armonioso de todos los niños y niñas.

Nuestra Constitución acogió estos lineamientos internacionales al consagrar en el artículo 44 los derechos fundamentales de los niños.

La familia, la sociedad y el Estado tienen la obligación de asistir y proteger al niño para garantizar su desarrollo armónico e integral y el ejercicio pleno de sus derechos. Cualquier persona puede exigir de la autoridad competente su cumplimiento y la sanción de los infractores.

La parte final del Artículo 44 de nuestra Constitución establece los principios básicos de los derechos de los niños: como son el interés superior y la prevalencia de derechos de la infancia sobre los derechos de los demás". ${ }^{2}$

1 Pacto de la UNICEF: Convención de los derechos del niño.

2 Constitución política de Colombia. Editorial Leyer. 2009. Art. 44
Estos derechos y principios fueron desarrollados a través de la llamada Ley de Infancia y Adolescencia, Ley 1098 de 2006, que consagra todos los derechos de la niñez y establece los mecanismos y entidades encargados de hacer efectivos esos derechos.

El Artículo 20 del Código de la Infancia y Adolescencia, establece que los niños deben ser protegidos contra toda forma de abandono físico, explotación económica por parte de sus padres o de cualquier persona vivan o no con el menor; al uso de sustancias psicoactivas, la violación o inducción a la prostitución, y otras variadas formas de vulneración de los derechos de los niños y adolescentes.

Este mismo artículo 20, establece también la protección del patrimonio del menor. El numeral 16 reza: "Los menores deben ser protegidos: Cuando su patrimonio se encuentre amenazado por quienes lo administren".

Es posible que se crea que la vulneración de los derechos patrimoniales no es algo trascendente para el menor. Sin embargo, y a pesar que las conductas que se describen en el artículo 20 resultan más lesivas tanto física como psíquicamente para los menores, no podemos dejar de resaltar la importancia que puede tener para un menor el que su patrimonio no sea cuidado en debida forma, sea por sus padres o por su curador o quien tenga a su cuidado el patrimonio, pues el despilfarro y deterioro patrimonial pueden generar un problema muy grave para su establecimiento económico futuro.

Ni que decir frente a la reflexión sobre la procedencia de dichos bienes, pues es injusto que unos administradores despilfarrenloque un padre, abuelo, un tío o cualquierotro 
pariente le hayan dejado al niño pensando en su futuro y que al cumplir éste la mayoría de edad, dicho patrimonio se haya deteriorado o haya desaparecido. Por ello es importante salvaguardar sus bienes teniendo en cuenta que despilfarrar el patrimonio de un menor es una forma cruel y aberrante de atentar contra él.

La ley establece los siguientes mecanismos para la protección de los bienes del menor:

En primer lugar encontramos los procesos de guardas. Los cuales tienen por finalidad dar asistencia y representación a todos los menores de edad que carecen de padres, para que cumplan las obligaciones de cuidado personal y las emanadas de patria potestad, es decir, la administración, usufructo de los bienes del menor o discapacitado mentalmente, así como su representación legal.

En segundo lugar encontramos los procesos de rendición de cuentas. Los cuales tienen por objeto que quien administra bienes de menor o persona con discapacidad, rinda cuentas de su administración.

También encontramos el proceso de inventario solemne de bienes. Con este proceso se persigue que el padre que se encuentre ejerciendo los derechos de administración de bienes y representación del menor, no los vaya confundir con los que va a adquirir dentro de su nuevo matrimonio y que se sepa a ciencia cierta con que bienes cuenta el menor al momento del matrimonio de su representante.

Y por último el proceso de licencia para enajenar o gravar bienes del incapaz. Tiene por objeto la protección del patrimonio del menor imponiendo al representante legal la obligación de solicitar licencia para enajenar o gravar, con garantía real los bienes inmuebles, o La venta o empeño de bienes muebles preciosos que tengan valor de afección para el incapaz. ${ }^{3}$

Lo que se pretende plantear aquí, son varias situaciones:

\section{La primera consiste en que los bienes requieren de la} mencionada autorización.

El artículo 303 del Código Civil, consideró necesaria esta exigencia de autorización judicial tan sólo tratándose de bienes raíces (sic) del hijo; y el art. 1o. de la Ley 67 de 1930, hace extensible (sic) tal exigencia a la enajenación de derechos hereditarios del menor sometido a patria potestad o guarda ${ }^{4}$.
Se concluye que la licencia para enajenar bienes de menores, sólo lo exige cuando se trata de bienes inmuebles, y de derechos sucesorales, mas no de bienes muebles, aunque el valor de dicho mueble sea alto, aún más que el de un inmueble. Por ejemplo la venta de tracto mulas o maquinaria pesada de alto costo y que tiene la categoría de bienes muebles, ni lo bienes incorporales tales como los derechos de autor, y derechos de propiedad intelectual, entre otras.

Así también lo ha entendido la jurisprudencia, quien en sus diferentes fallos lo ha manifestado así. Revisemos por ejemplo la Sentencia No. T-554/94. De la Sala Primera de Revisión de Tutelas de la Corte Constitucional con fecha del cinco (5) de diciembre de mil novecientos noventa y cuatro (1994) contra la Secretaría de Tránsito de Bogotá quien se negó a tramitar la solicitud de traspaso de propiedad, de un vehículo adquirido por el actor, porque perteneciendo el automotor a unos menores de edad, los cuales los habían adquirido en la sucesión de su padre, era necesario acreditar la autorización judicial para la venta.

El juez ante quien se solicitó, inadmitió la demanda argumentando: “... la ley sustancial (Art. 303 del C.C) exige autorización judicial tan sólo tratándose de bienes raíces (sic) del hijo y el art. 1o. de la Ley 67 de 1930, hace extensible (sic) tal exigencia a la enajenación de derechos hereditarios del menor sometido a patria potestad o guarda."

La norma es clara: "la autorización es sólo para bienes raíces, por lo tanto, la venta de bienes muebles de un menor, no debe ir precedida de la referida licencia judicial".

Sin embargo, lo anterior no es predicable para los guardadores o curadores del menor, pues el artículo 483 del Código Civil, hace extensible esa autorización a aquellos muebles considerados como preciosos o con algún valor de afección, características que, en determinado momento, puede poseer un automóvil, por su valor comercial. Esto justifica la solicitud de la referida licencia, por parte del guardador y, será el juez quien, según las circunstancias propias del caso, determine si hay lugar o no a ella.

Lo que quiero significar es que si quien hubiese estado
en administración de las tracto mulas hubiese sido un 
ISSN-2248-736 * Número 3 * Revista Facta Non Verba

guardador, dicha licencia si hubiera sido necesaria para el traspaso de los vehículos, conforme a la interpretación del artículo 483 del Código Civil.

No puede perderse de vista que la finalidad del citado artículo, es la protección del patrimonio del menor como uno de sus derechos, lo que por sí sólo justifica la exigencia de dicha licencia, manifestó la Corte.

Ahora bien, otra situación que tenemos, es que la referida licencia deberá ser otorgada por el juez con conocimiento de causa, como lo establece la parte final del ya mencionado artículo 303, es decir, sabiendo para que se pretende enajenar dichos bienes, el espíritu de la norma deja ver que la venta de dicho bien debe ser para mejorar la calidad de vida o las condiciones de vida del menor.

Así lo expuso ante el Tribunal Superior del Distrito Judicial de Tunja, Sala Civil - Familia, el Magistrado Ponente: Luis Humberto Otálora Mesa. Mediante Sentencia con fecha del dieciocho (18) de abril de dos mil siete (2007). Por medio del cual, decide el Tribunal el recurso de apelación interpuesto contra la sentencia de primera instancia, proferida por el Juzgado Civil del Circuito de Moniquirá dentro del proceso de JURISDICCIÓN VOLUNTARIA adelantado por CORONA ANGELA NIÑO DE GONZÁLEZ y OTRA. Dentro del cual las demandantes pretenden que en la sentencia se decretara el levantamiento de la reserva de usufructo otorgada a su favor dentro de escritura pública de compraventa con reserva de usufructo $y$, se autorizará la venta en pública subasta del inmueble. Al respecto manifestó el Tribunal: "En cuanto toca con la licencia para enajenar la nuda propiedad sobre el inmueble, que es de lo que ciertamente son titulares los menores, es menester decir que es asunto regulado por el artículo 303 del Código Civil ya citado.

La razón de ser de este mandato legal estriba en la necesidad de evitar que los representantes de los menores, en este caso las madres, en desarrollo de las facultades que les otorga la patria potestad, puedan disponer de los bienes raíces de sus hijos que han llegado a su administración por efecto de su calidad dentro de un sentido de arbitrariedad, con desmedro de los intereses del menor que por su propias circunstancias está en imposibilidad de ejercer una adecuada defensa de los mismos. Ante tal situación, ha querido la ley establecer unos mecanismos que depuren tales acciones de esa arbitrariedad para restringirlas a actos que sean no solamente bien intencionados sino que correspondan a una auténtica necesidad y conveniencia del bienestar de los menores. Y para el cabal y acertado logro de ese propósito consideró la ley que quien estaba en mejor aptitud de lograr su objetivo era el juez de familia a través de un proceso donde se pudiera controvertir esa conveniencia, la cual emitía la autorización con el lleno de los requisitos indicados por el artículo 653 del C. de P.C.

Dada la finalidad de la licencia judicial, tal determinación, como se apuntó en el fallo apelado, solamente puede surgir en presencia de una certeza en el proceso, cuyo acto obedece exclusivamente al propósito de lograr mejorar la situación tanto personal como económica del menor. Dicho de otra manera, solamente con la certeza de que la autorización traerá un beneficio al menor, la demanda de licencia podrá ser acogida.

Ahora bien, el trámite de este proceso es de jurisdicción voluntaria ante un Juez de Familia del lugar de residencia del menor o incapaz, una vez demostrados y verificados por el juez los motivos que se aducen para la venta del bien, se autoriza mediante sentencia la venta o enajenación del bien, la cual deberá REALIZARSE EN PÚBLICA SUBASTA.

Una vez cumplida la venta mediante este mecanismo, termina la función del juez que ha conocido de este trámite, con las siguientes precisiones:

1) El autorizar la venta de bienes de incapaces o de los declarados ausentes, se ordenará hacerla en pública subasta, para lo cual, se procederá conforme a las disposiciones del proceso de sucesión, previo avalúo del bien. 2) Si se trata de permuta, el juez ordenará que por perito se avalúen uno y otro bien, para tener en cuenta la diferencia de precios y se completen al que hubiere lugar.

3) Las objeciones al avalúo se decidirán por auto, ya que no es apelable.

4) Cuando se conceda la licencia o autorización, en la sentencia se fijará el término dentro del cual deba utilizarse, que no podrá exceder los seis meses y una vez vencidos, se entenderán extinguidos.

"Desafortunadamente, en la práctica, el término de seis meses para la venta del bien resulta muy corto, ya que muchos jueces exigen para el avalúo y remate del bien, que éste se haya embargado y secuestrado previamente, lo que implica que se comisione a la autoridad competente para que practique la medida, sometiéndose a la disponibilidad de tiempo que tengan para tal fin".

UNA DOBLE MEDIDA CAUTELAR, embargo y secuestro para un bien que no lo requiere, por cuanto las medidas cautelares persiguen por excelencia asegurar los efectos de la futura sentencia, de tal manera que el embargo cumple con esta finalidad en la medida en que 
está preordenada a hacer efectiva la sentencia que en el proceso habrá de dictarse, es decir, pretende contrarrestar la posible inejecución de la sentencia, es decir, quiere evitar lo que la doctrina ha llamado el periculum in damni y el periculum in mora.

En cuanto al primero, tenemos que el peligro de daño que se pueda ocasionar con el no cumplimiento de la sentencia y en cuanto al periculum in mora, que constituye el fundamento de las cautelas, no basta que el interés en obrar nazca de un estado de peligro y que la providencia invocada tenga por ello la finalidad de prevenir un daño solamente temido, sino que es necesario que además de la inminencia del peligro, la providencia solicitada, tenga carácter de urgencia, en cuanto sea de prever, que si la misma se demorase, el daño temido se transformará en daño efectivo o se agravará el daño ya ocurrido.

Pero aquí no se ocasiona ningún daño. El daño se configura cuando el juez no puede cumplir su sentencia por que han desaparecido las condiciones fácticas que 10 hacen inejecutable. Por ejemplo; el objeto principal de la pretensión ha sido transferido a terceros, pero ¿Cómo podría transferirse a un tercero, un bien que está a nombre de un menor, sin el respectivo permiso o licencia para enajenar el bien? Entonces necesariamente tendremos que concluir que no existe la posibilidad de que no se cumpla la sentencia sin el embargo del bien inicialmente.

Ahora bien en cuanto al posible daño privado, que consiste en que no se satisfaga la pretensión, tenemos entonces que dicha pretensión procura la autorización para vender o enajenar bienes que se encuentran a nombre de un menor, y que sin esta licencia, no hay manera de transferir un bien que esté a nombre de un menor, sino es a través de este trámite o proceso, por lo que no se configuraría un daño para el menor.

De tal manera podemos concluir que las medidas cautelares serían inoficiosas en este proceso por las razones ya expuestas.

Surge entonces otro planteamiento: ¿Quién verifica que efectivamente los dineros producto de esta venta sean invertidos o manejados para mejorar la calidad de vida o el patrimonio del menor? El legislador se quedó corto en este proceso, por cuanto no existe autoridad o entidad que vigile o verifique que efectivamente el dinero, fruto de esa venta, se invierta exclusivamente al propósito de lograr mejorar la situación tanto personal como económica del menor.

3) Nuestra legislación trata de establecer algunas sanciones para quienes no administren bien los dineros producto de esa venta. Sanciones que encontramos en el Código Penal en el artículo. 236 que norma: "El que malverse o dilapide los bienes que administre en ejercicio de patria potestad, tutela o cúratela en ascendiente, en adoptante, cónyuge o compañero (a) permanente, incurrirá en prisión de uno a dos años y multa de uno a diez salarios mínimos legales mensuales vigentes, siempre que la conducta no constituya otro delito". 5

Este tipo penal restringe el delito a los miembros de un mismo núcleo familiar, pues si quien administra bienes en ejercicio de una guarda no es familiar de su pupilo, la conducta está penalizada en el Art. 259 del C.P. que norma: "El que malverse o dilapide los bienes que administre en ejercicio de tutela o curatela, incurrirá en prisión de uno (1) a dos (2) años, siempre que la conducta no constituya otro delito."

Estos tipos penales, son de tipo subordinado, es decir, que se tipificarán siempre y cuando la conducta aquí descrita no quepa en otro tipo que le prescriba una pena superior. 6

Pero con la pena establecida el delito sería excarcelable $\mathrm{y}$, por tanto, la sanción no sería suficiente para la conducta. Adicionalmente, el delito ya no sería competencia del Juez de Familia que autorizó la venta, ni tampoco su concepto es vinculante dentro del proceso penal.

Desde el punto de vista civil podría iniciarse un proceso de rendición de cuentas, pero este proceso solo tendría eficacia para indemnizar al menor, si quien administraba el patrimonio del menor, posee bienes propios. De lo contrario, sólo quedaría la vía penal y como ya se analizó, la ley penal no tiene penas fuertes para las posibles conductas que se configurarían.

Por lo tanto podemos concluir que la decisión central quedará huérfana de cumplimiento y por ello es que se erige en deber judicial el comportamiento destinado al acatamiento de lo dispuesto, de conformidad con el ordenamiento.

Autores contemporáneos hablan de que la nueva tendencia de la dirección material del proceso sea ubicada, no tanto en la dirección procesal, como en la dirección post procesal. En estos casos, el juez tiene incluso un deber más fuerte de dirección post procesal, su pasividad post procesal podría significar la vulneración efectiva del derecho ya que, como se sabe, las sentencias por sí solas nada significan sin ejecución efectiva de la misma. Las sentencias no son por sí mismas garantías intrínsecas de que los derechos han de ser respetados a menos que dichas sentencias efectivamente se cumplan. Es así como considero pertinente la creación de unos juzgados de seguimiento de sentencias en el área de familia, a fin de que los fallos sean efectivos en la finalidad de la decisión dada por el juez.
5 Código Penal Colombiano. Editorial Leyer. Artículo 236.

6 Ferro Torres, José Guillermo. Delitos contra la Familia. Pagina 821. 